\title{
Re-evaluating Value in Faith-Based Social Action
}

Faith-based social actors have always played a significant part in welfare and care (Prochaska, 2006), though their visibility diminished somewhat after 1945 when many welfare services were professionalised in the British welfare state, a process which also happened across Europe in varying ways (Dinham, 2015). Since 1980, the extension of an increasingly mixed economy of welfare has recalibrated the roles of state and others. It has both advanced and made more visible the participation of faith groups as they are looked to across developed economies to plug gaps in provision (Dinham, 2011; 2015). With this has come greater levels and methods of scrutiny, with the attendant requirement for evaluative measurement, designed to hold providers to account. This has been criticised for narrowing and instrumentalising faith groups - what Bretherton calls 'commodification' (Bretherton, 2010). This presents the challenge of developing evaluative tools that meet the requirements of policy makers and funders while at the same time working for faith groups and communities more meaningfully.

This article considers this challenge through the lens of a practice research project which implemented an existing Third Sector evaluative tool in a small number of faith-based settings. It begins with an exploration of the policy contexts which call forth accountability in the first place, and the place of faith groups within this. It goes on to consider models, understandings and contestations of evaluation. A methods section then sets out the research process, including some contextual material on the faith groups which participated. The findings are then presented and discussed before drawing conclusions about the implications for practice and future directions for research.

\section{Theoretical and Policy Contexts of Faith-Based Social Action}

Faiths have been re-emerging in the public realm in recent years in ways which have unsettled public thought and practice. Following Habermas, these have 
come to assume a largely secular settlement in which neutrality was the default position (Habermas, 2011). Sociology has been revisiting secularity in the light of this re-emergence, and there are important recent challenges to the secular assumption which is shown to be widely misunderstood and highly contested. Thus Brian Wilson's classic proposal that religion is losing its social significance (Wilson, 1966), though extended by Peter Berger's prediction that religion will disappear to a vanishing point (Berger, 1967), is counterposed by Grace Davie's observation that people are 'believing without belonging' (Davie, 1994). Danielle Hervieu-Leger inverts this to add that people are also 'belonging without believing' (Hervieu-Leger, 2006). In another strand, Linda Woodhead's evidence suggests that while traditional religion may be in decline, new spiritual and informal forms are thriving (Woodhead, 2012), which Steve Bruce dismisses, saying that all this religion talk is nothing but a last gasp before it finally disappears, as originally predicted (Bruce, 2011). So the story is one of change as much as decline, and a simple assumption of secularity is giving way to a recognition that the secular is not to be equated with simple neutrality, and that societies are neither simply secular nor simply religious but complexly both.

In this context, faith has been re-emerging in the policy arena too, and theoretical contests have played out here, not least in debates about nomenclature. The preference among policy makers has been for 'faith' which has come to represent the main religious traditions recognised by government. It is broadly accepted as a sort of imperfect best, rooted in the multicultural paradigm and evolved into a multifaith equivalent (see Dinham, 2012). An alternative designation arises from the Equality Act 2010 which adds 'religion or belief' to the list of protected characteristics, defining religion or belief as stretchy categories, including the religious traditions and also informal and resurgent modes, like spirituality, Druidism and Paganism, non-religious beliefs, like secularism and humanism, 'non-religion' such as atheism and agnosticism, and beliefs deemed in law, such as environmentalism. 
A third strand in renewed public talk appears as 'Religious Literacy', itself a contested concept arranged around the notion that the public sphere has lost the ability to talk about religion just as it has become visible again (see Dinham and Francis, 2015). Recognising the contests, this study uses the term 'faith' because it has been the preference of the policy-makers who frame the community practices examined. They are described by them as 'faith-based' providers, and have emerged in the public realm in three ways: as providers of welfare and social services; as contributors to 'community cohesion' through social capital, or as detractors from it through radicalism and violent extremism; and in extended forms of participatory governance such as neighbourhood management (Dinham et al., 2009). This article is predominantly interested in the first arena: provision of welfare and social services.

\section{Faith, Community and Welfare}

There is a body of research which shows that faith communities have long been highly active in care and welfare initiatives, most notably at community level. In this they stand in a long tradition of working with people, particularly in disadvantaged areas, to achieve change and development. It has been argued that this arises out of "an holistic, faith-based view of communities which values and dignifies all people" (Finneron et al., 2002:12).

Prochaska suggests that faith-based service provision is rooted in Victorian philanthropy, when society "boasted millions of religious associations providing essential services and a moral training for citizenry..." (Prochaska, 2006: 2). In his view, the Victorians "believed that religion and the public good were inextricably linked" (Prochaska, 2006: 3) and that "charity could only be effectively exercised under the influence of sacred principle" (Prochaska, 2006:3). This was a time when there were "2,349 subsidiary associations to dispense the Bible" (Prochaska, 2006:17) and the "myriad parish societies...had membership numbers that varied from under ten to hundreds" (Prochaska, 
2006:17-18). Thus for de Toqueville, Christianity was "not an opiate, nor a morality of slaves but a religion of self-discipline and personal service that answered social and political needs" (in Prochaska, 2006:26).

When practically every aspect of social service, from health, to the family and community development came under the auspices of central government in the period after 1945 (Timmins, 1995; Dinham, 2015), this was a period of high idealism whose effect, despite all good intentions, was to recast the widespread, experienced and highly effective network of non-government providers, many of which were faith-based, as outside the strategic idealism of government. But in turn, the dawning realisation that the post-war welfare consensus would not result in the eradication of society's 'five great evils' led in the 1950s and after to renewed enthusiasm for community-based policies rooted in neighbourhood and self-help (see Younghusband, 1968) - precisely the sorts of work faith-based providers had been so good at.

But it was the shift to "market led approaches in the 1980s and early 1990s" (Mayo et al., 2003:28) which really extended and made visible once more spaces for faith-based activities, and this was characterised by a focus on the economic, as opposed to community, development of local areas and the 'trickle down' approach to wealth. It also marked a conscious shift towards provision of public services, not solely by government, but also by voluntary sector agencies and community bodies. This took place via a proliferation of local and national government contracts and partnerships, especially under the Labour governments between 1997-2010, when the voluntary and community sector, and faith groups within that, played increasingly significant roles as providers, especially at local level. This was echoed in the US where the Faith-Based Initiative, operated from the White House, stimulated and encouraged contracting of public services to faith groups too (see Black et al., 2004). This culture of contracting, in turn provides an impetus for measuring those activities in ways 
which hold them to account: as they gain distance from government, they come under increased scrutiny.

Since 2010 in the UK, this emphasis on partnerships and contracting between faith bodies and government has continued in the rhetoric. However, local authorities, which had been the primary source of such contracts, have experienced reductions in their budgets of up to $40 \%$, diminishing the number of contracts issued to faith-based and other Third Sector providers. At the same time, the support infrastructures for faith-based contributions which were built up under the Labour governments between 1997-2010 were rapidly dismantled after 2010, when a Liberal Democrat-Conservative coalition was formed (2010-2015), and then a Conservative majority government in 2015. It was announced in 2010 that the nine Regional Development Agencies (RDAs) set up in 1998 would close, taking with them very significant resources, including the funding of regional multifaith fora in each, which had provided strategic networking and training opportunities to faith-based partners (see Dinham, 2012; Beckford et al., 2006). The central government 'Faith Communities Capacity Building Fund' of $£ 12$ million to build local capacity among faith groups to provide services and cohesion was abolished. The Faith Communities Consultative Council, which had been established to advise the Secretary of State for Communities and Local Government, was disbanded. New Labour's 'Compact on Relations between Government and the Voluntary and Community Sector', published in 1998 (Home Office, 1998) was replaced in ways which were widely seen as almost complete dilution (Zimmeck, 2010). Previously this had guaranteed the independence of the voluntary sector, and its right to campaign, to comment on government policy, and to challenge it. By contrast, the Transparency of Lobbying, Non-party Campaigning and Trade Union Administration Act was passed in England and Wales in 2014, restricting the amounts that may be spent or donated by Third Sector bodies in periods preceding elections, and requiring consultant lobbyists to register before lobbying. In this context, The Baring Foundation's Independence Panel calls for 'a new settlement between the Government and 
the voluntary sector, underpinned by a far deeper understanding from the state about why the independence of the sector enables it to make a distinctive and important contribution to society' (Baring Foundation, 2015, introduction), including 'Reform [of] commissioning and procurement to get the best out of the voluntary sector and to recognise the value it creates' (ibid). Alongside these developments, the minimum size of government contracts has been increased to such levels as effectively to exclude many faith-based providers, and funding for support infrastructure has been withdrawn in this area too, for example in relation to the 'Funding Central' online portal provided by the National Council of Voluntary Organisations (NCVO), which has moved from a grant-funded service, free at the point of use, to a subscription model.

This all poses challenges and opportunities. Key amongst these is how the faith contribution is understood, valued, used and demonstrated: how it is measured and evaluated, and what this reveals about faith in the public realm.

\section{Value and Evaluation Contests}

Evaluation is itself a contested notion. Quality services are those that are needed by users or a particular cause, well run, assessed and improved, shown to make a positive and measurable difference and continuously developed in order to achieve the very best results. However, a quality organisation may or may not provide good quality services and may or may not have an impact upon people, communities or other organisations. Likewise, change may be expressed as outputs or outcomes. Outcomes approaches observe overall changes, benefits, learning or other effects that occur in individuals and organisations as a result of services and activities provided by an organisation (see Ellis, 2009; Walker, et al., 2000). Outputs, on the other hand, measure only those tangible, practical products which result from action and not the process of achieving them. 
The Charity Evaluation Services (CES, now part of NCVO) attempts to synthesise the distinctions, describing quality as being about excellence in the way that an organisation is run, in service delivery and in achieving the very best results (see CES 2004:4). This stands in contrast to 'impact', which Church and Skinner (2006:5) describe as "enduring, broad and sustainable" and relating to the longer-term mission of an organisation.

According to Ellis (2009) and Westall (2009), the requirements of funding bodies and commissioners have resulted in a recent shift towards measurable outcomes and an evidence-based performance focus for voluntary and community organisations. Nevertheless, the Quality Standards Task Group recommended that funders, regulators and commissioners should reduce the burden on voluntary and community organisations (VCOs) by focusing on outcomes - what changes - rather than imposing prescriptive requirements (NCVO, 2004:6).

Walker, et al. (2000:13) welcome this, suggesting that it effectively surmounts the temptation merely to measure what is measurable, such as the activities and physical changes, rather than what is important, such as the enduring effects on people and communities. At the same time Walker concedes that the purpose of collecting evidence of outcomes should not merely be to provide a report to funding bodies and to achieve a kite mark, but also to provide information for an organisation to reflect upon how appropriately it is performing and to what degree of quality.

Likewise, Ellis (2009) reviews twelve quality systems and categorises them into three distinct groups. The first group concerns quality standards that do not require information to be provided about service user outcomes in order to meet their standards. These standards, for example, Customer First and ISO 90001, focus on how things are done, the internal procedures and the quality of delivery, but do not require evidence about the results of the organisation's activities. The second group is quality standards that ask whether an organisation conducts 
effective monitoring and evaluation of the outputs and services it delivers, but does not ask about the overall outcomes achieved, for example, Volunteer Centre Quality Accreditation. The third group is standards that require an organisation to show evidence that positive outcomes have been achieved as well as being concerned with internal procedures and monitoring and evaluation systems.

A broader concept of value, outcomes and impacts is reflected in the 'Social Return On Investment' (SROI) framework. This involves stakeholders in determining outcomes and puts financial values on the significant social and environmental changes identified by them (see Arvidson et al, 2013). Similar systems use more practitioner-based measures and focus upon 'distance travelled' rather than outcomes (see Westall, 2009).

Across the range of approaches is a key theme: that evaluation can be much more than an exercise in obtaining a quality mark. It can be a means of ensuring internal practices are up to date and compliant; provide assurance for service users; support volunteer, staff and trustee recruitment; drive direction and strategy; and give confidence. Many argue that evaluation is not therefore a moment but a process, and a continuous cycle of assessment, improvement and review is desirable (see Murphy, et al. 2010:23; Faithworks, 2008:64-67). This renders evaluation reflective rather than instrumental.

\section{Project and Methods}

In these contexts, the research reported on here was undertaken as a knowledge transfer partnership (KTP), designed to explore these issues of measurement in faith-based social action. Data were collected in 2009-2011, and reflective work in workshops among the research team and partners was designed to further iterate the findings by sharing the learning with the participants through to 2013 . This resulted in online films intended for use more widely, on topics arising in the 
study, and an online workbook designed to help other projects to adopt a reflective measurement process should they wish to.

The original research to be 'transferred' was undertaken in two earlier projects (in 2006 and 2007-08) which generated detailed knowledge about the value of faithbased organisations in community social action. The first project (Dinham, 2006) systematically reviewed 'grey' research residing at regional and community levels across England to produce a national dataset of faith-based activities in social action. This revealed a highly fragmented and impressionistic map of activity which was both frustrating and tantalising. Taking all the self-reported activities in each of these research reports together, there was clearly a very significant amount of faith-based community and social action taking place in each of 48 types of work which emerged (see Dinham and Shaw, 2011). 
This brings in to focus a problem with measurement at national level since each region and community level project was using locally differentiated language and methodology. This inhibited comparability and the ability to communicate effectively between areas.

The second project, supported by the UK government Department of Communities and Local Government (DCLG), considered the potential for national indicators or 'domains' for measuring faith-based social action. These were developed in a two-day workshop with purposively sampled policymakers, researchers and practitioners in faith-based settings, using participatory community development processes and values. Participatory community development techniques were used to induce these domains and this led to the conclusion that the challenge is to measure quality in faithbased settings in ways which develop the activity rather than merely 'demonstrate' it or show it off. The project called this process 'measurement as reflection' (see Dinham and Shaw, 2011).

The KTP that resulted involved a process to test this out in faith-based settings. The project identified a faith-based partner, the Faith-Based Regeneration Network, and a non-faith-based one, Community Matters, both engaged in supporting community development work in local settings ${ }^{1}$. FbRN was chosen because it of its role as a national umbrella network of faithbased social action projects, with direct connections to government in one direction and the grass roots in the other. Community Matters was selected because it had over many years developed and used a mainstream community measurement tool - called VISIBLE - which uses reflective evaluation in voluntary and community settings. This could be used to test out the applicability of non-faith-based approaches in faith-based settings, as the project required. The study is qualitative and can not reliably be generalised. However the findings are indicative of the issues discovered within this particular sample, and are intended to give rise to reflections on their efficacy more widely.

\footnotetext{
${ }^{1}$ The former has significantly reduced its presence since the KTP work was undertaken, and the latter closed down in 2016
} 
The partnership worked in seven faith-based settings, reflecting on the process throughout to ask two key questions:

1. Are faith-based settings reflective in their assessments of their action?

2. Do mainstream tools articulate value in faith-based settings or are new, distinctive tools required?

The seven projects were selected following an application process, advertised through FbRN's database of 9000 contacts. It took in to account the following factors in making the selection: geographical spread; a range of faith traditions; and a range of types of community service or project. These were designed to ensure inclusivity, on the basis that the project involved knowledge which should be 'transferred' with an eye to equal opportunity to participate. The selection criteria were not in themselves research variables, and thematic analysis has not been undertaken with reference to the differing categories. The projects included five faith traditions (Christian, Hindu, Jewish, Muslim, and Sikh) and a multi-faith group. They were all English, to minimise complicating analysis because of differing administrative arrangements in Scotland, Wales and Northern Ireland. They were located in the North West, the Midlands, London and the South West. Two were registered charities. The others were community groups which used the process to prepare for charitable status. They differed in size from annual incomes under $£ 10 \mathrm{k}$ to incomes more than $£ 100,000$. Between them they offered community support on issues including cohesion, education, health care, and sport. All the projects except the multi-faith one were located in faith buildings. In each setting we spoke to at least one leader, one worker and one service user.

The study carried out semi-structured depth interviews $(n=18)$ to explore experiences of working with the VISIBLE tool, asking about its adequacy and appropriateness in capturing what they valued as quality. It also interrogated what the process implied for projects' own development. This was used to explore the degree to which mainstream tools, as represented by VISIBLE, would fit in faith-based projects to measure quality as a process of reflection. 
An assessment of the fit between VISIBLE and these faith-based projects revealed continuities and discontinuities within and between faith-based settings as well as non-faith-based counterparts, and reveals underlying contests in the notion of faith in the public realm.

\section{Evaluation as Reflection}

Overall the project indicated a move away from evaluation as mere scrutiny towards an approach which has genuine usefulness to the evaluated settings and their users. The main reason why these faith-based organisations undertook an evaluation process was to seek improvement in a process of reflection.

"I would argue that when we get almost in to a routine of doing that [reflection and evaluation] it certainly helps us from the projects' point of view but it may be something analogous with our own lives as people of faith and indeed as faith communities to begin to do that ourselves"*2 $^{2}$

Participants said that tools for measuring quality are valued most in faithbased settings when they are also used to reflect.

"Stop every now and then, take notice of where you are, take notice about what's happened and have a think about where you're going next."

Participants also noted a difference between measuring an organisation and measuring the activities of a faith community which acts as the organisational structure: 'communities' are real spaces in which real people live while organisations are structures in which people work. They emphasised faith communities as spaces of solidarity and relationality, not simply organisational structures.

\footnotetext{
${ }^{2}$ Quotes are unascribed throughout in order to preserve participants' anonymity.
} 
"[The tool] definitely comes across as something that's got localised community groups at heart ....it's keeping in mind targets, but outcomes and all the other things that are important, so [it's] for organisations where[as] it is about dealing with people"

Participants took this further, saying that faith-based social action is marked out by a disposition towards reflection anyway, in the form of wisdom and attentive hospitality - factors which they think aid a reflective nature. They commented that seeking to welcome the stranger and to offer service as hospitality to everyone unlocks an organisation to be open to new possibilities and challenges from unexpected people and places.

“....We can't differentiate, he's poor or he's rich no, there is no difference between any person. So a beggar, he can sit with us and have food, there's no 'no, no you can't sit here."'

In this way, evaluation was seen as a process of building solidarity and relationality and faith was seen as connecting directly to faith-motivated service.

Leadership was seen as an important element in this relationality. Participants said that a central issue in achieving evaluation as reflection is how leadership is approached.

"More support from the trustees would have been the resource I would have been looking for which hasn't really come"

Projects had previously rejected alternatives to the tool which was used in the study because they were inflexible, did not reflect their faith-based values, and tended to be led from the 'top down'. Participants distinguished between leadership on processes (especially getting started) and leadership on values. They also distinguished between leadership styles and leadership structures. 
"...we try to be quite a light organisation bureaucratically, as working class community that is one thing that can stifle and kill, is to have too much paper work too many committees, too much official organisation very very important but a lot of things in a community like this tend to happen informally and I mean at the sessions even with steering committee members, we have our meetings absolutely but a lot of the stuff gets worked out, talked about, discussed, debated while the kids are playing basketball among the parents, the mums and occasionally the dads"

A collaborative approach was preferred by the actors in this sample of faithbased social action settings. Participants said that their way of working is collaborative, bottom-up, consensual, inclusive and empowering. Referring to the relationality of communities, they noted how this relies on community development skills and 'bottom-up' facilitative approaches as much as on being entrepreneurial.

A crucial part of the process undertaken in this study was the provision of a mentor to work with each pilot project - something not used as standard in the usual process in mainstream settings. The project introduced this element to facilitate the reflection both researchers and settings needed to do to understand the 'fit'. Participants in this study also valued the process of mentorship. The project conducted semi-structured interviews with mentors $(n=7)$ which, with the further interviews with participants in the projects $(n=18)$ showed that the mentoring role was felt to be highly valuable.

"I think they've (mentor and programme manager) been totally supportive because if you go to either of them and ask for support you get it, so they have been supportive"

They concluded that mentorship introduces a chain of action which is invaluable to the 'evaluation as reflection' process. They felt that the mentor in a sense 'joins the community' rather than providing it with consultancy and that settings develop a 'thinking head' in an evaluation process which is 
supported by a mentor. Thus the mentoring relationship was seen as part of humanising the evaluation process, 'warming it up' and setting the 'professional' in the context of relationships. It was seen as an aspect of the hospitality which faith-based settings said was important to them. For this reason they did not link professionalism necessarily to a quality mark. They noted that being measured against professional standards does not guarantee either a professional service or one that is well-experienced by service users. They wanted to stress the importance of relationships as well as processes. They also found this affirming.

"Internally my approach to quality has always been using it as a way of reviewing, if you are looking for a quality mark using it as a way of reviewing what you are doing, then the mark in itself internally is less important than the work that it enables you to do."

Thus the process of evaluation was seen as more important than the outcome and participants distinguished between instrumental and values-based evaluation, with the first seen as focused on satisfying funders and regulators and the second seen as serving to improve services in response to need and in line with beliefs and values.

\section{Public Faith as Transparency}

This raises the question whether faith-based settings need a tool that measures and reflects the faith-base itself, or only the action which results. Participants spoke of their religious faith when discussing the values underpinning their work.

"...if you're not providing, then any Sikh organisation fail[s] to fulfil [its] commitment."

They felt that this tool provided space for their values to be expressed and measured, even though it does not specifically ask about faith, and they thought this balanced the imperatives of secular privacy and public 
transparency. At the same time, they expressed caution about making any claim that faith values are different or distinctive to other forms of social action. They recognised that all social action organisations have a value-base and also that faith and non-faith groups may share values.

"I am very wary of, very wary of suggesting any faith-based organisations has qualities and values that are not found in other organisations because I don't think we have any particular claim on goodness, integrity, generosity and all that"

Others said that there was sometimes a difference between faith-based and other services, and failure to capture this might sometimes inhibit engagement.

"All these organisations have values of equality or openness but...and importance on relationships [sic]...but there is something about our ethos as a faith-based, that in a sense does make it really quite hard for groups like CVS [Council for Voluntary Service] to really understand what drives us"

In terms of this 'specialness', participants referred to their faith as a deep emotional commitment underpinning their social action.

"... what drives me, and I would agree with absolutely what A. was saying, that it's my Islamic motivation to do good and to help others whatever faith they are"

They said it made them feel passionate about their role in the local area, about the organisation and the needs it meets, and about the relationship between their faith and their service to others, sometimes described as 'working out theology in practice'.

"...evaluating our work is incredibly important for perspective, you know you get so engaged in the work, that ability to step back to evaluate 
and to reflect and I would say as well from a spiritual point of view that's quite important because that is what God wants and needs us to do, to be able to step back a bit from our lives, to be able to see ourselves to an extent through God's eyes and get that sort of perspective"

"I mean we have a lot of volunteers and those volunteers do what they do as part of their Christian conviction"

Nevertheless, there was ambivalence about whether to voice the faith-base publicly. Participants emphasised evaluation which captures how values are put in to practice. At the same time, evaluation was seen as important because of its role in making faith-based organisations transparent and therefore accountable. They said that evaluations should include the extent to which an organisation offers its services and activities to all, regardless of religion, belief or none, the experience of welcome and hospitality it offers, and the way it conducts its business in an open and transparent way.

"The doors open and they open automatically for a very good reason because we want everyone to feel welcome so whoever's walking past, the doors will open, there's no judgement going on here, you don't have to worry if the doors will open for you, whether you're welcome in there or not because the doors automatically open and for us umm that's I think very distinct, I mean we are saying you are welcome you are of value, we will offer you hospitality, we will offer you God's love"

This challenges the common Habermasian assumption, referred to above, that faith-based services must somehow be neutral or private about the faithbase of their action. All of the participants in this study said that they felt it wrong to evangelise through their social action. Services must be offered without conditions. But they also said that, as their faith underpins their passion, this could usefully be expressed, for example in promotional material, in such a way as to sharpen the vision and communicate the ethos. 
This was seen as having the potential to enable an evaluation to be made of the extent to which both faith and secular values are respected:

"Well we are Christian; we don't hide it."

Expressing religious reasons for faith-based social action may be an important aspect of being accountable therefore, since it spells out why a service is being offered, who it is intended for, and what it might feel like to use the service. While participants were clear that services should not 'feel' religious, some felt that being explicit in materials about the beliefs and values underpinning them would provide a fuller 'flavour'.

At the same time, some participants observed in this study that there may be appropriate reasons why faith-based organisations might sometimes restrict services, for example to female Muslims or orthodox Jews who would not otherwise use the service and may feel they have no alternative. Participants felt that such provision is sometimes reasonable, but noted that the approach taken by the quality tool used in this research requires provision without conditions in order to achieve the quality mark. They suggested that a more nuanced understanding of what might motivate conditions on provision in some cases would be helpful if a service is to reach certain constituencies who would otherwise themselves feel excluded, and that tools are needed which can measure this positively.

This is a critical point because a lack of clarity about what motivates faith groups can be a cause of tension when external funders and partners are wary or sceptical of working with them. Some interviewees remarked that given the scepticism that faith-based organisations sometimes experience from funders and commissioning bodies, it may turn out to be increasingly important for faith-based organisations to become more transparent about what they do, why and how they do it as they tender to supply services.: 
"[Partners]...can't get, umm sometimes uneasy I suppose that we can be doing what we say we are doing without some sort of other agendas attached, that they're naturally quite worried about"

“...we've got the word Faith in our organisation...and we've been mulling over for the past year about, you know, having that word in our actual name.."

\section{Conclusions}

The project makes two main conclusions. The first concerns the importance of reflection in ensuring that evaluation makes a difference, rather than simply being an instrumental exercise. This enjoins the importance of relationality as a basis of 'humanising' evaluation and connecting to relationships of sincerity and solidarity. The second concerns the disruption of assumptions about the role of faith in the public realm and how these affect practices of faith-based social action and how they are publicly accountable. The debates are deeply sociological, about the binaries and boundaries between the secular and the sacred, and the public and the private.

This question of the public role of faith emerges as central in this study. None of the faith-based social action settings in the sample wished to evangelise. Nevertheless, they thought that evaluation can help refocus on and articulate the faith underlying faith-based social action. They thought this was important for ensuring the work is well understood in terms of what it is, where it comes from and what service provision will feel like to users. This suggests that the 'faith' in 'faith-based' could be publicly spelt out as a way of being more accountable and transparent. Despite Habermasian assumptions of a public sphere in which religion is discussed only in what Habermas calls public (nonreligious) 'reasons', it seems possible from the sample in this study that reflective measurement could help defuse concerns about evangelisation and 'services with strings attached' by spelling out what is being provided, for whom, with what reasons and goals, and by what methods. The challenge should not be underestimated. It requires nothing less than a wholesale 
reassessment of assumptions about the secular basis of public and community life, and their interaction with the public policy which scrutinises it.

\section{References}

Ahmed, R., Finneron, D., Miller, S. and Singh, H. (2006) Tools for Regeneration: Practical Advice for Faith Communities ( $2^{\text {nd }}$ edition). London: Faith-based Regeneration Network UK (FbRN).

Allen, A. and May, C. (2007) Setting Up for Success: A practical guide for community organisations. London: Community Development Foundation.

Arvidson, M., Lyon, F., McKay, S., and Moro, D. (2013) Valuing the Social: The nature and controversies of measuring social return on investment (SROI) Voluntary Sector Review, 4(1), 2013: 3-18(16)

Ashdown, J. (2010) Community action and faith-based community work. in Crucible, The Christian Journal of Social Ethics, July-Sept 2010.

Baring Foundation (2015) An Independent Mission: the Voluntary Sector in 2015 London: Baring Foundation

Barr, A. and Hashagen, S. (2000) ABCD Handbook: A framework for evaluating community development. London: Community Development Foundation

Beckford J, Gale R, Owen D, Peach C and Weller P (2006) Review of the Evidence on Faith Communities London: Office of the Deputy Prime Minister

Billis, D. (ed) (2010) Hybrid Organisations and the Third Sector, challenges for practice, theory and policy Hampshire Palgrave 
Black A E, Loopman D L and Ryden D K (2004) Of Little Faith: the politics of George W Bush's Faith-Based Initiative Washington DC: Georgetown University Press

Boyatzis R (1998) Transforming Qualitative Information London: Sage

Bretherton L (2010) Christianity and Contemporary Politics Chichester: WileyBlackwell

Charity Evaluation Services (2004) Quality and evaluation in voluntary and community organisations, Guidance paper 3: key terms and definitions. London: CES.

Church, C. and Skinner, S. (2006) Change Check: a practical guide to assessing the impact of your community organisation. London: BASSAC.

Dinham A (2006) Faiths and Frontiers on the Starship Social Enterprise: boldly going as faith-based entrepreneurs London: FbRN

Dinham, A. (2007) Priceless, Unmeasureable: faith-based community development in England in the 21st Century. London: FbRN UK.

Dinham A., Furbey R., and Lowndes V., (eds) (2009) Faith in the Public Realm: problems, policies, controversies Bristol: Policy Press

Dinham, A., and Shaw, M. (2012) Measurement as Reflection in Faith-Based Social Action, Community Development Journal 47(1):126-141

Ellis, J. (2009) Bringing outcomes in to focus in quality. London: CES Quality Conference 25/6/09.

Faithworks (2008) Ethos, effectiveness and excellence. London: Faithworks. 
Finneron, D., Green, L., Harley, S. and Robertson, J. (2001) Challenging Communities: Church Related Community Development and Neighbourhood Renewal, London: CUF/CCWA.

Habermas, J. (2011) "The political": the rational meaning of a questionable inheritance of political theology' in E. Mendieta and J. Vanantwerpen, (eds) The Power of Religion in the Public Sphere. New York: Columbia University Press.

Home Office (1998) Compact on Relations between Government and the Voluntary and Community Sector London: Home Office

McCabe, A. and Phillimore, J. with Mayblin, L. (2010) Understanding Third Sector 'Below the Radar' Activities: a Review of the Literature. Birmingham: Third Sector Research Council Briefing Paper No. 29.

Miller, S. (2007) Keeping it Together: a reflective practice tool for faith-based community development practitioners. London: FbRN UK.

Murphy, E., with Ellis, J. ( $1^{\text {st }}$ edition) and Smith, L. with Matthews, S. (2010) First Steps in Quality (2nd edition). London: Charity Evaluation Services.

NCVO (2004) Improving our Performance: a strategy for the voluntary and community sector: Executive Summary. London: NCVO.

Nicholls, J., Lawlor, E., Neitzert, E. and Goodspeed, T. (2009) A guide to Social Return on Investment. London, Cabinet Office.

Timmins N (1995) The Five Giants: a biography of the welfare state London: HarperCollins

Walker, P., Lewis, J., Lingayah, S. and Sommer, F. (2000) Prove it: Measuring the effect of neighbourhood renewal on local people. London, Groundwork, The New Economics Foundation and Barclays PLC. 
Westall, A. (2009) Value and the Third Sector: working paper on ideas for future research. Birmingham, TSRC Working Paper 25.

Winter, J. (2010) Practical Spirit: Interactive project development for faithbased organisations involved with social action. London: FbRN UK.

Younghusband, E. L. (1968) Community Work and Social Change: report of a study group on training set up by the Calouste Gulbenkian Foundation London and Harlow: Longmans

Zimmeck, M. (2010) The Compact 10 years on: government's approach to partnership with the voluntary and community sector in England, Voluntary Sector Review, (1): 125-33 